\title{
Desoneração da folha de pagamento e comportamento dos custos das empresas listadas no segmento de fios e tecidos da BM\&FBovespa
}

\section{Payroll tax relief and cost behavior of listed companies in the tissues segment of the BM\&FBovespa}

\author{
Mara Juliana Ferrari \\ Fundação Universitária para o Desenvolvimento do Alto Vale do Itajaí - UNIDAVI \\ mara@rossa.com.br \\ Professora na Fundação Universitária para o Desenvolvimento do Alto Vale do Itajaí - \\ UNIDAVI \\ Doutoranda no programa de Pós-Graduação em Contabilidade da Universidade Federal de \\ Santa Catarina - UFSC
}

\author{
Altair Borgert \\ Universidade Federal de Santa Catarina - UFSC \\ altair@borgert.com.br
}

Professor na Universidade Federal de Santa Catarina - UFSC

Doutor em Engenharia de Produção pela Universidade Federal de Santa Catarina - UFSC

Thayse Moraes Elias

Universidade Federal de Santa Catarina - UFSC

thaysemooraes@hotmail.com

Mestranda do programa de Pós-Graduação em Contabilidade na Universidade Federal de

Santa Catarina - UFSC

\author{
Aline Willemann Kremer \\ Universidade Federal de Santa Catarina - UFSC \\ alinekremer_@hotmail.com
}

Mestre pelo programa de Pós-Graduação em Contabilidade na Universidade Federal de Santa Catarina - UFSC

\section{RESUMO}

O objetivo deste artigo é identificar o comportamento dos custos das empresas listadas no segmento de fios e tecidos da BM\&FBOVESPA entre 2009 e 2015, período que compreende dois diferentes cenários, antes e após a desoneração. Admite-se como hipótese da pesquisa a redução dos custos no período posterior a desoneração da folha de pagamento. Em termos metodológicos, utiliza-se a linha de tendência e o Teste t, no sentido de verificar a existência de diferenças de médias dos índices antes e após a desoneração. Os resultados obtidos não fornecem evidência para rejeitar a hipótese nula, qual seja a de que a média da relação das variáveis Custo dos Produtos Vendidos/Receita Líquida de Vendas (CPV/RLV), Custos Totais/Receita Líquida de Vendas (CT/RLV) e Lucro Líquido/Receita Líquida de Vendas 
(LL/RLV) não se altera com a medida, o que não permite afirmar que a desoneração da folha de pagamento impactou nos custos, nas despesas e na margem de lucro das empresas analisadas. Palavras-chave: Comportamento dos custos. Desoneração da folha de pagamento. Segmento de fios e tecidos.

\begin{abstract}
The objective of this study is to identify the cost behavior of the companies from the tissue segment, registered on BM\&FBOVESPA, between 2009 and 2015, a period that comprises two different scenarios, one before and one after the payroll tax relief. The hypothesis of the research is that the costs should reduce in the period after the governmental measures. The method of this paper comprises the use of trend line and the t-test, in order to verify if there is any difference on the indexes' mean before and after the tax relief. The results do not provide evidence to reject the null hypothesis, which indicates that the ratio of the variables Costs of Goods Sold/Revenue, Costs of Goods Sold and General and Administrative Expense/Revenue and Net Profit/Revenue does not change with the payroll tax relief. As a result, it does not affect the costs, the expenses and the profit margin of the companies analyzed.
\end{abstract}

Keywords: Cost behavior. Payroll tax relief. Tissue segment.

\title{
1 INTRODUÇÃO
}

Nos últimos 20 anos, o governo brasileiro desenvolveu reformas econômicas e políticas que, de alguma forma, afetaram a sociedade, com reflexos tanto na organização interna das empresas quanto nas relações entre os setores público e privado. Segundo Oliveira (2000), na década de 1990, a discussão política sobre as reformas assumiu uma característica distinta, com maior ênfase para o denominado "Custo Brasil".

A Confederação Nacional da Indústria - CNI (1995, p. 9) define o Custo Brasil como o "conjunto de ineficiências e distorções que prejudica a competitividade do setor produtivo". Complementarmente, Oliveira (2000) ressalta que tal definição envolve diversos fatores como o déficit público, os elevados custos de transporte, a crescente carga tributária e os custos associados ao trabalho e à previdência. Consequentemente, muitos desses componentes, que fazem parte das planilhas de custos das empresas, são responsabilizados pelo baixo potencial competitivo da indústria brasileira. Ao que compreende os aspectos tributários, Kertzman (2012) destaca o impacto dos encargos sobre a folha de pagamento na atividade empresarial, bem como na própria economia brasileira.

Recentemente, o governo brasileiro estabeleceu um novo mandato institucional ao adotar medidas para desonerar a folha de pagamento, por meio da redução dos encargos sociais, com o objetivo de incentivar a legalização da mão de obra e estimular a competitividade das empresas. Tais medidas se fundamentam na Lei n. 12.546/11 - viabilizada pelas Emendas Constitucionais n. 20/98 e n. 42/03 - que substitui a contribuição previdenciária patronal de $20 \%$ sobre a folha de pagamento por uma nova alíquota, que pode variar de $1 \%$ a $2 \%$ sobre o 
faturamento das empresas, dependendo do setor. Em agosto de 2015, estas alíquotas foram majoradas, conforme a Lei n. 13.161/15, para percentuais que variam de 2,5\% e 4,5\% com efeitos a partir de 2016.

$\mathrm{Na}$ desoneração da folha de pagamento, dentre outras, a Lei n. 12.546/11 incluiu atividades do setor têxtil que, segundo Vieira (1995), tem uma participação histórica e decisiva no processo de desenvolvimento industrial brasileiro. De acordo com a Federação das Indústrias do Estado de Santa Catarina (2011), o setor têxtil é intensivo no uso da mão de obra e tem sido dominado por países asiáticos como a China, Indonésia, Índia, Bangladesh, Taiwan e Turquia. Esses países fornecem produtos por um custo significativamente inferior se comparado às empresas brasileiras.

Dentre os custos que compõem a produção na indústria, tanto da prestação de serviços como do comércio, tem-se o da mão de obra. Esse, por sua vez, é composto por elementos como salários, remunerações, encargos trabalhistas, previdenciários, entre outros tributos que incidem sobre a folha de pagamento. Tais elementos sofrem impactos diretos e indiretos de medidas governamentais de proteção ao emprego, dos sindicatos das categorias mediante as convenções coletivas dos trabalhadores e dos tributos, como os encargos sociais. Para Banker, Byzalov; Chen (2012); Guenther; Riehl; Robler (2014) essas leis, na maioria dos casos, apresentam-se de formas inflexíveis o que, possivelmente, dificultam o gerenciamento das empresas com relação à mão de obra, bem como levam os empresários a demonstrar um comportamento dos custos com características, também, de inflexibilidade.

No entanto, o governo brasileiro instituiu medidas com finalidades de flexibilização e de desoneração da folha de pagamento, por meio da redução dos encargos sociais. Assim, sob o aspecto da desoneração, pressupõe-se que as empresas passam a ter menos tributos sobre a folha de pagamento e, consequentemente, diminuem o custo da mão de obra, o que resulta na diminuição, também, dos custos e despesas de modo geral. No entanto, observa-se que, ao mesmo tempo, tal medida onera o faturamento das empresas, uma vez que as empresas passam a contribuir com um novo percentual para o governo.

Diante do contexto apresentado, busca-se resposta para o seguinte problema de pesquisa: qual o impacto da desoneração da folha de pagamento no comportamento dos custos das empresas brasileiras listadas no segmento de fios e tecidos da BM\&FBOVESPA entre 2009 e 2015 ?

Justifica-se a realização deste estudo pela relevância das informações de custos para acadêmicos, bem como para os profissionais ligados diretamente às empresas, cujas bases de sustentação de muitas decisões estão no conhecimento de como os custos se comportam 
(MEDEIROS; COSTA; SILVA, 2005). Desta forma, surge a necessidade do conhecimento sobre o fenômeno em referência, de que maneira o mesmo interfere nos custos e quais os resultados apresentados antes e após as medidas tributárias de desoneração da folha de pagamento do segmento têxtil de fios e tecidos.

\section{FUNDAMENTAÇÃO TEÓRICA}

Esta etapa reúne trabalhos relacionados ao assunto objeto do estudo. Pretende-se, com isto, identificar pesquisas e conceitos relevantes para auxiliar na compreensão do tema e, assim, encontrar respostas ou direcionamentos para o problema anunciado. Para tanto, apresenta-se, primeiramente, uma discussão acerca das medidas governamentais que fundamentam a desoneração da folha de pagamento e, posteriormente, pesquisas relacionadas ao comportamento dos custos.

\subsection{Desoneração da folha de pagamento}

A desoneração da folha de pagamento teve início em 2011 com o lançamento do plano “Brasil Maior". Primeiramente, apenas quatro setores foram contemplados: confecção, couros e calçados, "call centers" e softwares e tecnologia da informação e comunicação. Este plano tem como objetivo empreender uma ação transformadora sobre o padrão de investimento e competitividade da indústria e dos serviços, ao estimular a criação de novas competências e a consolidação de um ambiente propício aos negócios, de modo a promover um aumento da produtividade da indústria brasileira (PLANO BRASIL MAIOR, 2013).

Para tanto, o plano tem como foco a inovação e o adensamento produtivo do parque industrial brasileiro com o objetivo de obter ganhos sustentados de produtividade e do trabalho. Neste sentido, o governo brasileiro instituiu medidas como a desoneração tributária e, após dezembro de 2011, alterou a contribuição previdenciária de alguns setores, dentre os quais o setor têxtil, principalmente o segmento que produz artigos destacados no anexo II da Lei n. 12.546/11, conforme a Nomenclatura Comum do Mercosul - NCM, código estabelecido pelo governo brasileiro e adotado por outros países com o propósito de classificar e descrever mercadorias.

A Lei n. 8.212/91, cuja redação foi dada pela Lei n. 9.876/99, fundamenta a forma anterior à desoneração. No art. 22, preceitua que a contribuição patronal a cargo da empresa tem por alíquota o percentual de $20 \%$ e sua base de cálculo é o total das remunerações pagas, 
devidas ou creditadas aos empregados, trabalhadores avulsos e serviços prestados por terceiros no decorrer do mês. Ou seja, sua incidência tem por base a remuneração dos trabalhadores.

Com a intenção de aumentar a competitividade de vários setores, dentre os quais o têxtil, o governo estabeleceu por meio da Lei n. 12.546/11 a desoneração tributária, na qual incluiu a desoneração da folha de pagamento que, inicialmente, é vantajoso para os setores abrangidos com a redução dos impostos, maior oferta de crédito para as empresas, estímulos à inovação, exportação e financiamentos (PLANO BRASIL MAIOR, 2013).

Após a promulgação da referida Lei, outras medidas foram tomadas para definir alíquotas, setores abrangidos e incluídos no programa Brasil Maior, dentre as quais, a Medida Provisória n. 563/12, convertida na Lei n. 12.715/12, e posteriormente regulamentada pelo Decreto n. 7.828/12 e Instrução Normativa n. 1.436/13. Assim, por meio dessas medidas, vários setores foram incluídos na desoneração e determinou-se que a contribuição previdenciária de $20 \%$, calculada sobre o total da folha de pagamento de empregados, trabalhadores avulsos e contribuintes individuais, seja substituída pela aplicação das alíquotas de 1\% ou 2\% (alíquotas que anteriormente a MP n. 563/12 eram de 1,5\% a 2,5\%) sobre o faturamento, conforme o caso.

Para a base do cálculo utiliza-se o valor do faturamento, excluídas as vendas canceladas e os descontos incondicionais concedidos, bem como as exportações diretas, o Imposto sobre Produtos Industrializados (IPI), se incluído na receita bruta, e o Imposto sobre Operações relativas à Circulação de Mercadorias e sobre Prestações de Serviços de Transporte Interestadual e Intermunicipal e de Comunicação (ICMS), quando cobrado pelo vendedor dos bens ou prestador dos serviços na condição de substituto tributário.

Com o propósito de exemplificar a aplicação da lei na forma anterior e posterior à medida de desoneração, apresenta-se uma simulação do cálculo do INSS com base na proporção de $38 \%$ do custo da mão de obra em relação a receita bruta. Vale destacar que as informações de receita bruta e gastos com pessoal foram coletadas junto aos relatórios financeiros divulgados pelas empresas e referem-se à média de todas as empresas e períodos inseridos na análise.

Tabela 1 - Cálculo da contribuição previdenciária anterior e posterior a desoneração, em $R \$$

\begin{tabular}{l|r|r}
\hline Receita Bruta da empresa no mês & $1.000 .000,00$ & $1.000 .000,00$ \\
Total da remuneração - folha de pagamento & $380.000,00$ & $380.000,00$ \\
\hline \multicolumn{1}{c|}{ Cálculo de Recolhimento do INSS } & Anteriormente & Posteriormente \\
\hline Contribuição Previdenciária (20\% antes e 1\% após) & $76.000,00$ & $10.000,00$ \\
SAT (até 3\% sujeito ao adicional do FAP) & $11.400,00$ & $11.400,00$ \\
Salário Educação (2,5\%) & $9.500,00$ & $9.500,00$ \\
Terceiros (3,3\%) & $12.540,00$ & $12.540,00$ \\
\hline Total do custo de INSS para a empresa & $\mathbf{1 0 9 . 4 4 0 , 0 0}$ & $\mathbf{4 3 . 4 4 0 , 0 0}$ \\
\hline
\end{tabular}

Fonte: Dados da pesquisa. 
Conforme já mencionado, no período anterior à desoneração da folha de pagamento calculava-se o INSS com a aplicação da alíquota de $20 \%$ sobre a folha de pagamento. Já, após a desoneração, ao considerar que a atividade da empresa é totalmente enquadrada no Anexo II da Lei n. 12.546/11, e mantidas as proporções entre mão de obra e receita, aplica-se a alíquota de $1 \%$ sobre a receita (em alguns casos a alíquota é de $2 \%$, conforme art. $8^{\circ}$ da Lei n. 12.546/11), cujos valores se apresentam na Tabela 1.

Em resumo, como resultado da simulação apresentada na Tabela 1, pode-se verificar uma redução na contribuição patronal total de até $\mathrm{R}$ \$ 66.000,00 em relação à situação original, no caso de uma alíquota de $1 \%$ sobre o faturamento, o que representa um ganho em termos de redução dos custos empresariais.

Além da contribuição previdenciária patronal, existem outros tributos incidentes sobre a folha de pagamento como Seguro de Acidente de Trabalho - SAT e Salário Educação e Terceiros, os quais, por sua vez, não sofreram alterações com as medidas de desoneração. Desta forma, evidencia-se que a mudança afeta somente a contribuição patronal para o INSS. Os demais valores permanecem com incidência sobre o total dos salários, em média de 8,8\%.

A desoneração da folha de pagamento é constituída de duas medidas complementares. Em primeiro lugar, o governo eliminou a atual contribuição previdenciária sobre a folha e adotou um novo modelo sobre a receita bruta das empresas em consonância com o disposto nas diretrizes da Constituição Federal. E, em segundo lugar, essa mudança de base da contribuição, também, contempla uma redução da carga tributária dos setores beneficiados, porque a alíquota sobre a receita bruta foi fixada num patamar inferior àquela alíquota - a chamada alíquota neutra.

Identificam-se, no texto do Plano Brasil Maior (2013), múltiplos objetivos para as medidas de desoneração tributária instituídas pelo governo, dentre os quais: a) ampliar a competitividade da indústria nacional, por meio da redução dos custos laborais, e estimular as exportações, que são isentas da contribuição previdenciária; b) estimular ainda mais a formalização do mercado de trabalho, uma vez que a contribuição previdenciária passa a depender da receita e não mais da folha de salários; c) por fim, reduzir as assimetrias na tributação entre o produto nacional e o importado, ao impor sobre este último um adicional sobre a alíquota de Cofins-Importação igual à alíquota sobre a receita bruta que a produção nacional paga para a Previdência Social.

Assim, evidencia-se o propósito de reduzir custos laborais com as medidas apresentadas, mas ao mesmo tempo tem-se perda arrecadatória da contribuição previdenciária, o que pode acarretar problemas para a sociedade como um todo, conforme Kertzman (2012) e 
Ansiliero et al. (2008). O estudo de Kertzman (2012) verifica a viabilidade da desoneração da folha de pagamento, com a respectiva substituição da perda arrecadatória por outra base de financiamento. Tal estudo analisa a proposta do Governo de desoneração, bem como sugere um modelo de custeio da previdência social que traga vantagens em relação à tributação sobre a folha de pagamento. Outro aspecto comentado pelo autor refere-se aos custos sobre a mão de obra, mais especificamente quanto ao aumento da alíquota patronal das últimas décadas, que na origem da previdência era de apenas 3\% (Lei Eloy Chaves de 1923) e passou para os 20\%, o que demonstra, de certa forma, que os setores econômicos que utilizam intensivamente a mão de obra foram atingidos, e resultou no desestímulo à geração ou criação de empregos, visto o nível elevado dos custos trabalhistas.

Já, Ansiliero et al. (2008) apontam em seus estudos o que precisaria ocorrer, na massa salarial, para compensar a perda de arrecadação previdenciária, com relação à desoneração da folha. Para esses autores, a teoria econômica tradicional prediz a geração de ineficiências e desemprego causados pela tributação sobre a folha de pagamento, uma vez que há dois salários no mercado: o salário líquido recebido pelo empregado e o salário acrescido de tributos, recolhidos pelo empregador. Neste contexto, os autores concluem que a tributação sobre a folha de pagamentos é apontada como responsável pela elevação do custo do trabalho.

Em resumo, Kertzmann (2012) e Ansiliero et al. (2008) evidenciam os aspectos da perda da arrecadação previdenciária e o impacto para a sociedade, bem como apresentam alternativas para que este impacto não seja negativo, tanto no propósito de geração de empregos quanto no aumento dos custos da folha de pagamento. No entanto, não são apontados como propósitos dos seus estudos os impactos para as empresas, em termos de custos e resultados, das medidas governamentais. Mas, corroboram o aspecto do aumento considerável da contribuição previdenciária nos últimos anos ao acarretar o aumento dos custos da mão de obra.

Enfim, com base nos estudos apresentados, evidencia-se que as alterações nas contribuições previdenciárias sobre a folha de pagamento podem acarretar modificações nos custos das empresas e impactar nos seus resultados por meio de um possível aumento da lucratividade, bem como nas decisões que levam a aumentar, diminuir ou permanecer com o quadro de funcionários. Desta forma, pode melhorar ou não o desempenho organizacional e, consequentemente, a competitividade do setor.

Espera-se, como resultado da pesquisa, que os Custos dos Produtos Vendidos, bem como os Custos Totais, apresentem reduções após a medida de desoneração, ocasionado pela possível redução dos encargos. Não obstante, as empresas podem melhorar a Margem de Lucro como consequência da diminuição dos seus custos. 


\subsection{Comportamento dos custos}

Para Hansen e Mowen (2001) e Garrison, Noreen e Brewer (2007) o termo comportamento dos custos carrega em seu escopo as respostas de um custo em relação às mudanças nos níveis de atividades. Essas mudanças, que ocorrem em determinado período de tempo, são explicadas pelos direcionadores de custos, representados por alguma variável que casualmente afeta os custos como, por exemplo, o efeito de uma medida governamental.

Sob o aspecto de comparar os períodos anterior e posterior a uma medida, diante do impacto no comportamento dos custos decorrentes de decisões empresariais, Oliveira, Lustosa e Sales (2007) identificaram quais os impactos da privatização no desempenho operacional da Companhia Vale do Rio Doce. A análise dos efeitos desse evento baseou-se numa amostra de 20 observações para o período anterior à privatização e outras 20 observações para o período posterior à privatização, cuja motivação da pesquisa reside na importância da utilização de classificações de custos como parâmetros de análises. Para os autores, os custos primários, que estão relacionados a todos os custos diretos e variáveis de produção, mostram-se adequados para a análise, mas existe a necessidade de se observar a influência da legislação trabalhista brasileira na classificação dos custos com mão de obra, que transforma parte dos seus valores em custos fixos.

Oliveira, Lustosa e Sales (2007) aplicaram algumas alterações ao conceito originário de custos primários para identificar o desempenho da empresa em questão e avaliaram as características pré e pós privatização dos materiais diretos (proxy para custos primários). Neste sentido, salientam que no caso do Brasil o custo com a mão de obra direta identifica-se mais com o conceito de custo fixo, e justificam tal afirmação pelo fato de que a maioria dos empregados recebem remunerações fixas, e não por hora trabalhada. Por meio de técnicas estatísticas, os autores identificaram que os custos operacionais variáveis, no período posterior à privatização, sofreram significativa redução, fato que corrobora uma das expectativas propostas no trabalho. Concluiu-se que a privatização, sob o aspecto analisado, mostrou-se positiva, com os crescentes lucros e infere-se que a Companhia apresentou melhora no desempenho produtivo e operacional.

Quanto ao aspecto de análise por segmento, Richartz et al. (2011) analisaram as empresas catarinenses listadas no segmento de fios e tecidos da BM\&FBOVESPA no período de 1998 a 2010 e concluíram que, em média, 78,88\% da Receita Líquida de Vendas - RLV é consumida pelo Custo dos Produtos Vendidos - CPV. Além disso, essa representatividade não obteve alterações significativas (desvio padrão de 4,26) ao longo do período em análise. Em 
outro estudo, que contempla conjuntamente as empresas de Santa Catarina e Minas Gerais, Richartz et al. (2012) verificaram que a média da relação CPV/RLV se manteve em torno de $78 \%$, bem como identificaram que as empresas que possuem melhor relação CPV/RLV são as que apresentam menor Receita.

Posteriormente, por meio de estudos setoriais, Richartz e Borgert (2013) verificaram como se comportam os custos das empresas brasileiras listadas na BM\&FBOVESPA entre 1994 e 2011. No entanto, para identificar o comportamento dos custos foram verificados o perfil dos custos empresariais, tendências nos índices de custos, comparações dos custos por setores e análise da simetria do comportamento dos custos. Como resultados, os autores conseguiram traçar o comportamento dos custos das empresas brasileiras, com abertura de informações por setores e segmentos.

Sob o aspecto de medidas regulatórias, Ferrari, Kremer e Pinheiro (2013) pesquisaram o comportamento dos custos em função das mudanças regulatórias nas empresas listadas no segmento de Telecomunicações da BM\&FBOVESPA entre 1995 e 2012. Como resultado, encontraram que as maiores oscilações nos custos totais ocorreram até 2003, quando a legislação permitiu a entrada de novas empresas. Após esse período, percebeu-se a estabilidade da relação dos custos e das mudanças regulatórias, o que demonstra que os custos das empresas são afetados pela regulação do segmento.

Assim, para analisar a relação das medidas governamentais quanto à desoneração da folha de pagamento e o comportamento dos custos, no presente estudo utiliza-se dos preceitos apresentados por Oliveira, Lustosa e Sales (2007) para a comparação do período anterior e posterior a medida; Richartz e Borgert (2013), Richartz et al. (2012), quanto aos aspectos dos estudos de comportamento de custos em relação a segmentos específicos, em pauta o segmento de fios e tecidos; e Ferrari, Kremer e Pinheiro (2013) quanto ao impacto de medidas regulatórias, que implicam na inflexibilidade da estrutura da empresa, aspecto observado nas pesquisas de Banker, Byzalov e Chen (2012) e Guenther, Riehl e Robler (2014).

\section{PROCEDIMENTOS METODOLÓGICOS}

Para a realização deste estudo selecionaram-se as empresas com ações negociadas na BM\&FBOVESPA, no período de 2009 a 2015, do segmento de fios e tecidos. Tal procedimento se justifica pelo fato dessas empresas apresentarem as informações contábeis necessárias à realização dos cálculos do estudo, visto que os relatórios financeiros são divulgados de maneira pública aos usuários da informação. 
O segmento de fios e tecidos objeto de estudo é composto por 16 empresas. Destas, 6 empresas não apresentaram as informações necessárias às análises na base de dados utilizada. Portanto, o estudo contempla 10 empresas que disponibilizaram todos os dados necessários em todos os períodos, conforme o Quadro 1.

Quadro 1 - Empresas analisadas listadas na BM\&FBOVESPA

\begin{tabular}{|c|c|c|c|}
\hline Setor & Subsetor & Segmento & Razão social \\
\hline \multirow{10}{*}{$\begin{array}{c}\text { Consumo } \\
\text { Cíclico }\end{array}$} & \multirow{10}{*}{$\begin{array}{c}\text { Tecidos, } \\
\text { Vestuário e } \\
\text { Calçados }\end{array}$} & \multirow{10}{*}{ Fios e Tecidos } & Buettner S.A. Indústria e Comércio \\
\hline & & & Cia Fiação Tecidos Cedro Cachoeira \\
\hline & & & Cia Industrial Cataguases \\
\hline & & & Cia Industrial Schlosser S.A. \\
\hline & & & Cia Tecidos Santanense \\
\hline & & & Dohler S.A. \\
\hline & & & Karsten S.A. \\
\hline & & & Pettenati S.A. Indústria Têxtil \\
\hline & & & Teka-tecelagem Kuehnrich S.A. \\
\hline & & & Têxtil Renauxview S.A. \\
\hline
\end{tabular}

Fonte: BM\&FBOVESPA.

Destaca-se que as medidas governamentais de desoneração da folha de pagamento, após dezembro de 2011, aplicam-se a determinados segmentos classificados pelo Código Nacional de Atividade Econômica (CNAE) e pela Nomenclatura Comum do Mercosul (NCM) que identifica a natureza das mercadorias ou produtos e estão descritas conforme Anexos I, II e III da Instrução Normativa n. 1.436/13. Desta forma, pressupõem-se que tais empresas produzem os itens descritos e, assim, estão sujeitas a aplicação das medidas de desoneração.

Para as empresas selecionadas buscou-se as informações no banco de dados do software Economática referentes a Receita Líquida de Vendas - RLV, Custo dos Produtos Vendidos CPV, Despesas de Vendas - DV, Despesas Administrativas - DA e Lucro Líquido - LL. Acrescenta-se que os dados quantitativos foram reajustados pelo índice de inflação medido pelo IPCA com auxílio da própria base de dados. Feito isto, as informações foram exportadas para o software MS Excel. Neste software, com o apoio de pacotes estatísticos, verificou-se o comportamento dos custos das empresas antes e após as medidas de desoneração da folha de pagamento.

Além dos dados coletados na referida base, coletou-se o gasto com pessoal da Demonstração do Valor Adicionado, Receita Bruta das Notas Explicativas e número de funcionários do Formulário de Referência disponibilizados no site da BM\&FBOVESPA. Para fins deste estudo utilizou-se como Custos Totais - CT o CPV, DV e DA. Não se considera as Despesas Financeiras - DF por não possuírem relação direta com o volume de produção e sim com a estrutura de capital, o que resulta em certa variabilidade não condizente com as operações 
da empresa. Com o intuito de padronização e comparação, dividem-se o CPV, o CT e o LL pela RLV.

Com o propósito de visualizar o impacto da desoneração no comportamento dos custos apresenta-se a linha de tendência linear e a estatística descritiva da média das variáveis CPV/RLV, CT/RLV e LL/RLV, que abrangem todos os períodos de dados coletados. Destacase que tais análises são válidas para o conjunto de empresas observadas, portanto, não representam a média do setor. Vale mencionar que o emprego da Receita Líquida para análise dos Custos e Lucro objetiva verificar o comportamento destas variáveis no período compreendido. Não se trata, portanto, da referência à nova base de cálculo da desoneração, apenas uma base para análise.

Além dessas análises estatísticas, com a finalidade de fundamentar as conclusões, efetua-se o Teste t de Student unicaudal para verificar a existência de diferenças de médias das variáveis antes e após a desoneração para verificar se houve redução dos custos e aumento da margem de lucro. Para a realização do referido teste, que compara médias anteriores e posteriores a um fenômeno, é necessário que se tenha dados pareados, ou seja, a mesma quantidade de observações antes e após o evento. Portanto, realiza-se o teste com 11 trimestres anteriores a desoneração (primeiro trimestre de 2009 ao terceiro trimestre de 2011) e 11 trimestres posteriores a desoneração (quarto trimestre de 2011 ao segundo trimestre de 2014). Referido teste se sustenta nas seguintes hipóteses:

Ho: A relação CPV/RLV, em média, não se altera com as medidas de desoneração.

H1: A relação CPV/RLV, em média, diminui com as medidas de desoneração.

Ho: A relação CT/RLV, em média, não se altera com as medidas de desoneração.

H1: A relação CT/RLV, em média, diminui com as medidas de desoneração.

Ho: A relação LL/RLV, em média, não se altera com as medidas de desoneração.

$\mathbf{H}_{1}$ : A relação LL/RLV, em média, aumenta com as medidas de desoneração.

Diante do exposto, admite-se que o desempenho do segmento têxtil de fios e tecidos, observado por meio da ótica comportamental dos custos no período posterior as medidas de desoneração, é estatisticamente superior ao observado no período anterior à desoneração devido à redução dos custos do segmento. Evidencia-se tal desempenho por meio da rejeição das hipóteses nulas, as quais não caracterizam redução nos custos das empresas analisadas e aumento da margem de lucro. Assim, caso as hipóteses nulas sejam rejeitadas, os resultados indicam melhora no desempenho das empresas. 
Contudo, antes das análises, faz-se necessário a realização de um teste de normalidade dos dados, visto que este é um pressuposto para a utilização da estatística t. Neste estudo, devido ao tamanho da amostra, utiliza-se o teste de Shapiro-Wilk com um nível de significância de 5\% para todos os itens analisados.

\section{APRESENTAÇÃO E ANÁLISE DOS DADOS}

Para identificar quais foram os impactos das medidas governamentais quanto à desoneração da folha de pagamento das empresas do segmento de fios e tecidos, basicamente, busca-se analisar dois momentos distintos, antes da desoneração, quando a base de cálculo da contribuição previdenciária patronal era $20 \%$ sobre o valor da remuneração da mão de obra e após a desoneração, cuja base de cálculo passou a ser o faturamento das empresas com alíquotas diferenciadas por setores e produtos. Assim, comparam-se os dados dos períodos a fim de identificar alterações nos custos e resultados do segmento analisado.

Após a aplicação de testes de normalidade com nível de significância de 5\% nos dados utilizados, estes apresentaram distribuição normal de probabilidade no teste de Shapiro-Wilk para amostras pequenas. Assim, para iniciar as análises específicas quanto ao comportamento dos custos do período, antes e após as medidas de desoneração, apresenta-se na Tabela 2 a estatística descritiva da média das variáveis de todas as empresas para todos os períodos analisados, no sentido de uma visualização geral dos dados.

Tabela 2 - Estatística Descritiva

\begin{tabular}{lccc}
\hline \multicolumn{1}{c}{ Resumo Estatístico } & CPV/RLV & CT/RLV & LL/RLV \\
\hline Média & 0,8305 & 1,9608 & $-4,2728$ \\
Erro padrão & 0,0176 & 0,2807 & 1,1983 \\
Mediana & 0,8136 & 1,3426 & $-1,8387$ \\
Desvio padrão & 0,0917 & 1,4584 & 6,2265 \\
Coeficiente de variação & 0,1104 & 0,7438 & $-1,4572$ \\
Variância da amostra & 0,0084 & 2,1268 & 38,7691 \\
Curtose & 17,9037 & 7,7861 & 3,2668 \\
Mínimo & 0,7442 & 0,9698 & $-22,3316$ \\
Máximo & 1,2496 & 7,5524 & 0,7701 \\
\hline
\end{tabular}

Fonte: Dados da pesquisa.

Observa-se, na Tabela 2, que a média da razão entre custos totais e receita líquida de vendas é 1,9608, ou seja, os custos totais representam 196,08\% da receita líquida de vendas, cujo fato pode ser confirmado pela média do lucro líquido ser negativa. Em outras palavras, os dados mostram que, em média, as empresas deste segmento apresentaram um prejuízo de 427,28\% em relação à receita líquida de vendas para os trimestres em análise. Destaca-se, também, que os dados de LL são muito mais dispersos do que os demais, cuja situação é 
evidenciada por meio do coeficiente de variação de -1,4572 em comparação ao 0,1104 do CPV e 0,7438 do CT.

Na sequência, após uma análise geral dos dados, inicia-se uma análise mais detalhada sobre a influência da desoneração no comportamento dos custos. Esta análise detalhada compreende três etapas: 1) na primeira etapa analisa-se o comportamento dos custos com base nos dados de custo dos produtos vendidos, que busca identificar o impacto da desoneração sobre o processo produtivo dessas empresas; 2) a segunda etapa compreende o comportamento com base nos custos totais, que objetiva compreender, além dos custos produtivos, as despesas de vendas e administrativas; e 3) por fim, a terceira etapa analisa o efeito da desoneração sobre a margem de lucro das empresas, pois, ao afetar os custos, espera-se um efeito contrário no lucro, ou seja, ao reduzir os custos espera-se um aumento do lucro líquido.

É importante salientar que ao mencionar a intenção de analisar o impacto da desoneração sobre o comportamento dos custos, despesas e margem de lucro das empresas temse, especificamente, o objetivo de verificar se as alterações nos custos, despesas e margem de lucro das empresas ocorreram simultaneamente à aplicação da medida de desoneração, ao fornecer indícios de que o evento possa ter influenciado o desempenho das empresas. Portanto, não espera-se, com base nestas análises, identificar impacto direto da desoneração sobre as empresas.

\subsection{Análise CPV/RLV}

Neste tópico, busca-se identificar se a desoneração da mão de obra das empresas listadas no segmento de fios e tecidos da BM\&FBOVESPA afeta o custo dos produtos vendidos. Apresenta-se, na Figura 1, a tendência durante 27 trimestres compreendidos e a tendência anterior (até o $11^{\circ}$ trimestre) e posterior $\left(12^{\circ}\right.$ ao $27^{\circ}$ trimestre) a desoneração de forma desassociada. Assim, com as análises separadas do período antes e após o evento é possível compreender com maior detalhamento a tendência que os custos assumem em tais momentos. 
Gráfico 1 - Comportamento dos custos dos produtos vendidos

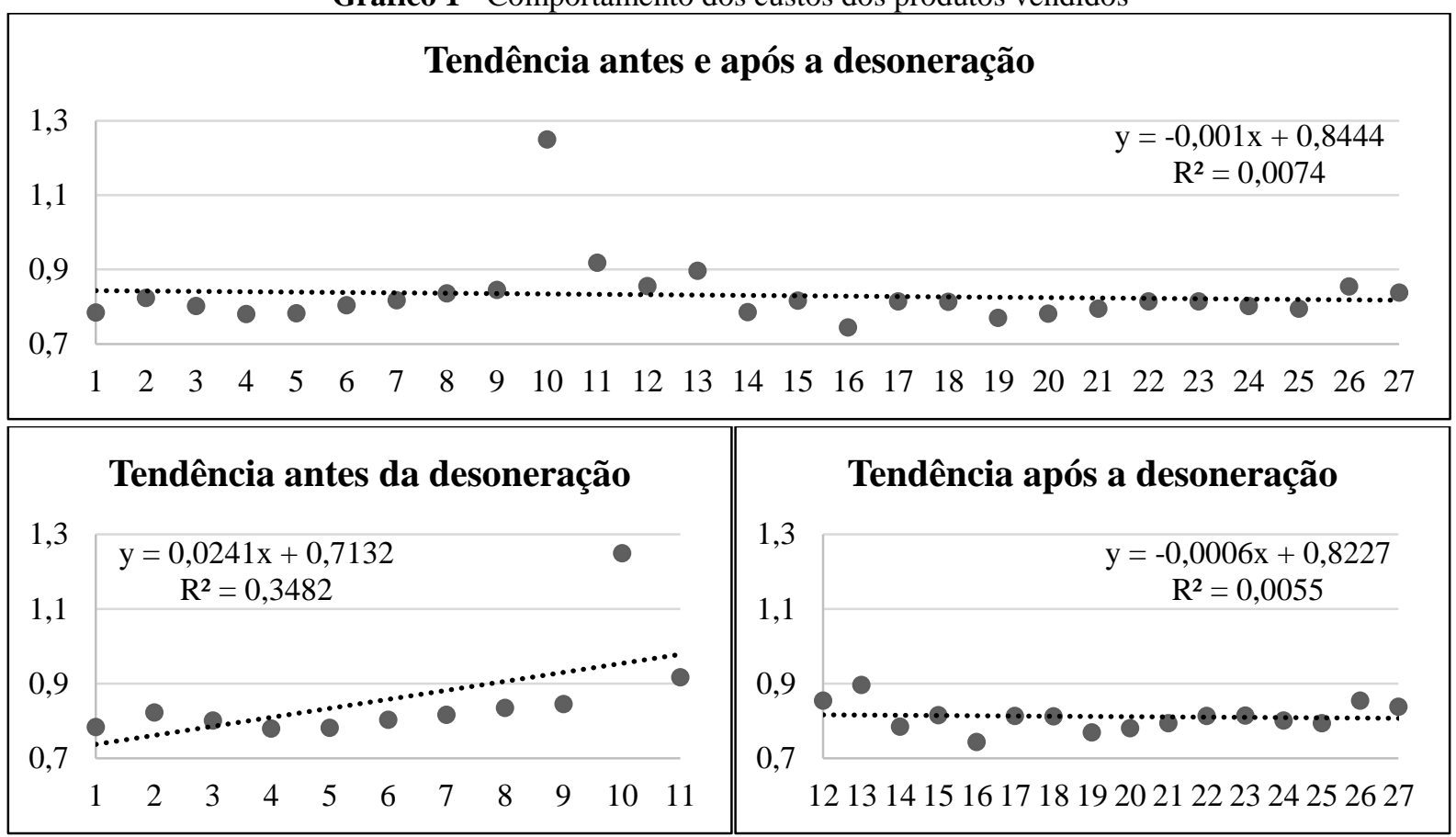

Fonte: Dados da pesquisa.

Verifica-se, na análise conjunta do Gráfico 1, que o comportamento dos custos dos produtos vendidos apresenta uma tendência de queda ao longo dos trimestres, conforme o coeficiente angular negativo. Contudo, observa-se com maior detalhamento na análise separada que, no período anterior a desoneração, a tendência é de ascensão, como evidencia a linha de tendência e o coeficiente angular positivo. No entanto, para o período após a adoção das medidas de desoneração o coeficiente angular é negativo, ou seja, há tendência de queda da relação CPV/RLV.

Embora a tendência dos custos do período anterior seja de aumento e a tendência do período posterior seja de queda, não se pode afirmar que a desoneração tenha influenciado nos custos das empresas analisadas, principalmente ao se observar a tendência agregada de queda dos dois períodos. Ainda assim, a desoneração da folha de pagamento pode ser um dos fatores que contribuíram para a queda na relação do CPV/RLV, em especial ao considerar o momento em que a redução ocorreu, que coincidiu com o período de aplicação da desoneração.

A fim de verificar se os dados antes e após o evento da Lei se alteram efetivamente e se as diferenças encontradas não são simplesmente casuais, elabora-se o Teste t de Student, conforme a Tabela 3. Essa estatística tem por objetivo testar a hipótese de pesquisa de que os custos apresentaram alterações com as medidas de desoneração. 
Tabela 3 - Teste t para relação CPV/RLV

\begin{tabular}{|c|c|c|}
\hline CPV/RLV & Antes & Depois \\
\hline Média & 0,85802 & 0,81153 \\
\hline Variância & 0,03213 & 0,01105 \\
\hline Observações & 10 & 10 \\
\hline Correlação de Pearson & & 0,7571 \\
\hline Hipótese da diferença de média & & 0 \\
\hline $\mathrm{gl}$ & & 9 \\
\hline Stat $\mathrm{t}$ & & $-1,2148$ \\
\hline $\mathrm{P}(\mathrm{T}<=\mathrm{t})$ uni-caudal & & 0,1277 \\
\hline t crítico uni-caudal & & 1,8331 \\
\hline
\end{tabular}

Fonte: Dados da pesquisa.

Por meio da Tabela 3 é possível perceber que, embora a média do CPV/RLV tenha diminuído de $85,80 \%$ para $81,15 \%$, o teste não fornece evidência para rejeitar a hipótese nula ao nível de significância de 5\%, de que a relação CPV/RLV, em média, não se altera com as medidas de desoneração, conforme valor $\mathrm{P}$ de 0,1277 . Em outras palavras, não se pode afirmar que houve efetiva redução dos custos e consequente impacto da desoneração da folha.

É importante destacar que a média do número de funcionários no período anterior a medida era de 2.069 contratados, no entanto, para o período posterior a desoneração, a média do número de funcionários é de 1.764, conforme disponibilizado pelas empresas observadas. Assim, a queda observada na média dos custos pode ser decorrência da queda do número de funcionários.

\subsection{Análise CT/RLV}

Com o objetivo de analisar não somente os efeitos da desoneração da folha de pagamento no $\mathrm{CPV}$, este tópico identifica o efeito no custo total das empresas, que abrange, além do custo dos produtos vendidos, as despesas com vendas e as despesas administrativas, para a compreensão dos seus efeitos no âmbito administrativo. Apresenta-se, no Gráfico 2, as tendências conjunta e separada, dos períodos antes e após o fenômeno descrito, em que a tendência conjunta abrange os 27 trimestres, a tendência anterior à desoneração refere-se aos 11 primeiros trimestres e a tendência posterior compreende do $12^{\circ}$ ao $27^{\circ}$ trimestre. 
Gráfico 2 - Comportamento dos custos totais
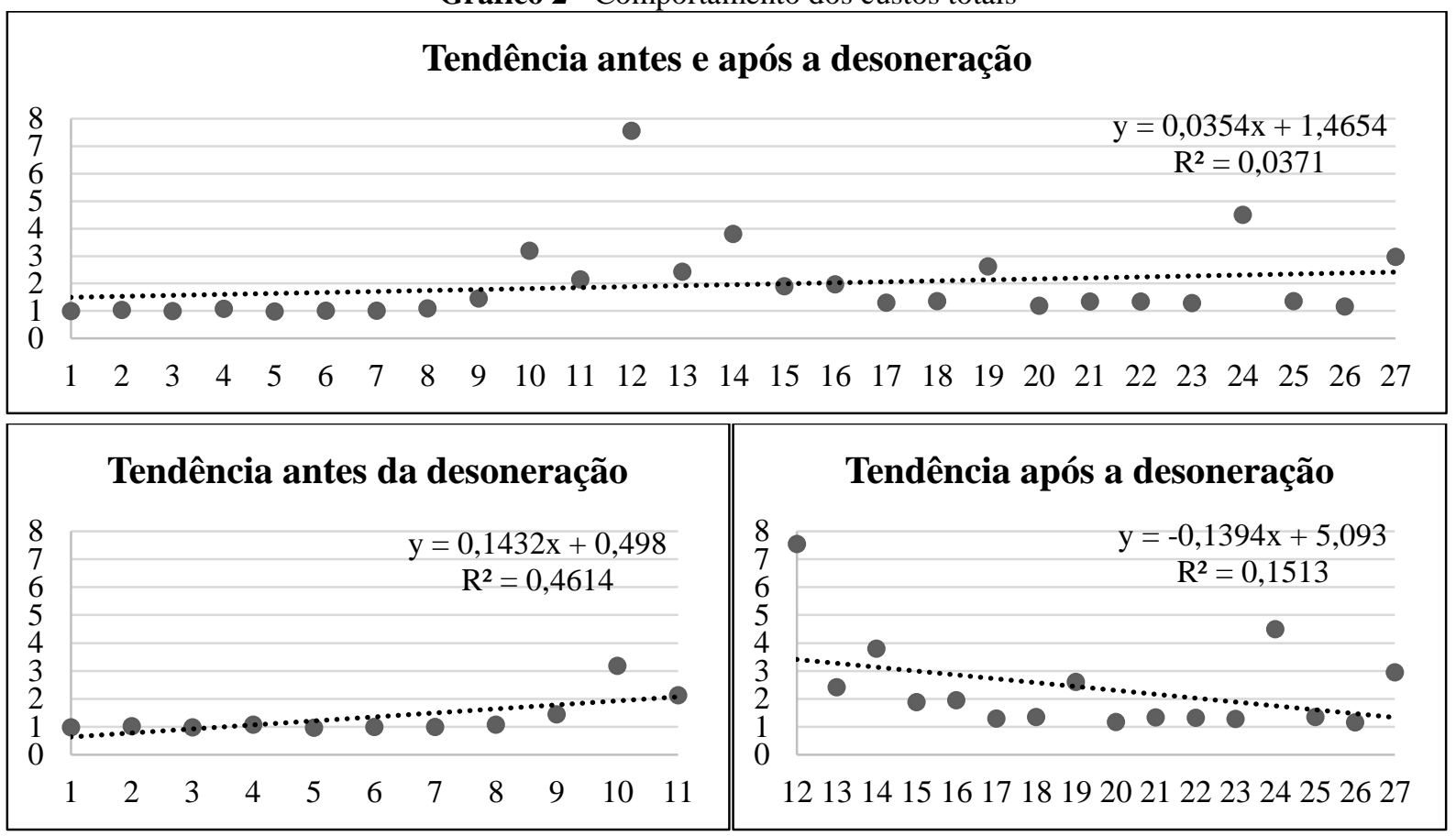

Fonte: Dados da pesquisa.

A tendência dos 27 períodos analisados apresenta um coeficiente angular positivo, ou seja, uma tendência de aumento. Assim como na análise do CPV, por meio das tendências individuais, pode-se perceber tendência de aumento da relação CT/RLV no período anterior à medida de desoneração e tendência de queda da relação no período posterior, com maior intensidade comparado a queda dos custos dos produtos vendidos. Vale destacar que a queda mais intensiva no período posterior a desoneração no CT em relação ao CPV aconteceu devido ao trimestre 12, em que o CT/RLV esteve muito acima da média e influenciou na tendência de todo o período.

Da mesma forma que na análise do CPV, não é possível inferir que a desoneração seja o principal fator responsável pela redução nos custos totais, ainda que a queda tenha ocorrida no período posterior a medida, mas esta pode ser uma das causas para a redução da relação CT/RLV. Por sua vez, utiliza-se o Teste t para identificar se há efetiva diferença nos dois períodos em análise, conforme segue na Tabela 4. 
Tabela 4 - Teste t para a relação CT/RLV

\begin{tabular}{|c|c|c|}
\hline CT/RLV & Antes & Depois \\
\hline Média & 1,3575 & 2,3755 \\
\hline Variância & 1,0612 & 18,5372 \\
\hline Observações & 10 & 10 \\
\hline Correlação de Pearson & & 0,9866 \\
\hline Hipótese da diferença de média & & 0 \\
\hline $\mathrm{gl}$ & & 9 \\
\hline Stat $\mathrm{t}$ & & 0,9774 \\
\hline $\mathrm{P}(\mathrm{T}<=\mathrm{t})$ uni-caudal & & 0,1769 \\
\hline t crítico uni-caudal & & 1,8331 \\
\hline
\end{tabular}

Fonte: Dados da pesquisa.

O Teste t, ao nível de significância de 5\%, não rejeita a hipótese nula como mostra o valor P de 0,1769, ou seja, não há evidência para rejeitar a hipótese de que a relação CT/RLV, em média, não se altera com as medidas de desoneração. Conforme mencionado, inclui-se no custo total o custo dos produtos vendidos, as despesas de vendas e administrativas. Assim, vale destacar a média da relação CT/RLV de 135,75\% antes da desoneração e de 237,55\% após a desoneração, que indicam aumento nas despesas com vendas e administrativas, uma vez que o CPV apresentou queda, quando observado a média.

\subsection{Análise LL/RLV}

Este último tópico de análise dos dados trata do impacto da desoneração na margem de lucro das empresas do segmento de fios e tecidos. Para a visualização do comportamento da margem de lucro apresenta-se o Gráfico 3 com a tendência durante os 27 trimestres compreendidos no total da observação, bem como as tendências anterior (até o $11^{\circ}$ trimestre) e posterior ( $12^{\circ}$ ao $27^{\circ}$ trimestre) a desoneração, de forma desassociada. 
Gráfico 3 - Comportamento da margem de lucro

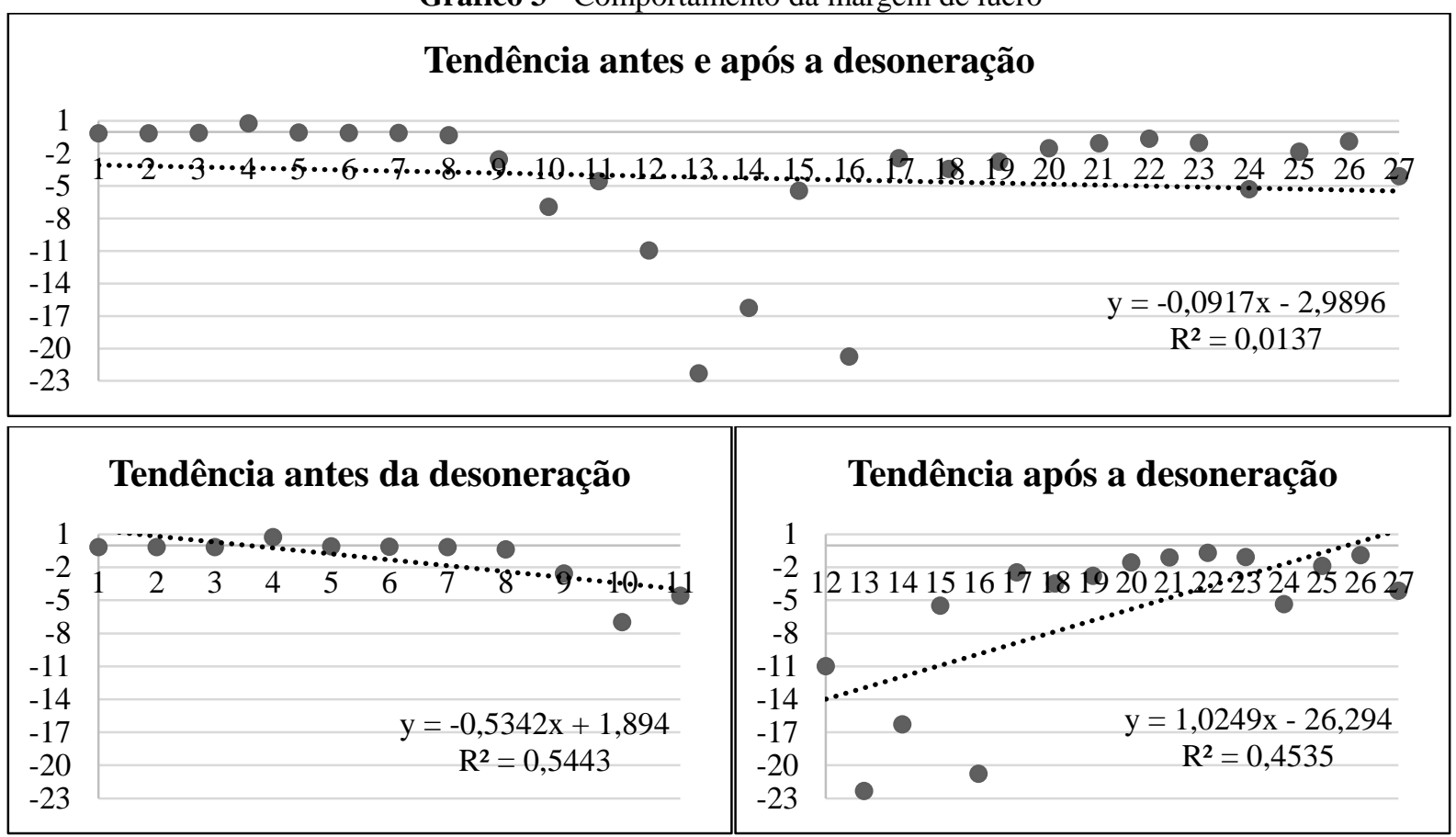

Fonte: Dados da pesquisa

Conforme se pode observar no Gráfico 3, a margem de lucro apresenta tendência de queda, quando observados todos os períodos abrangidos pela análise. A tendência do período anterior a desoneração também apresenta tendência de queda, de acordo com o coeficiente angular negativo. Mas, no período posterior a desoneração da folha de pagamento a tendência da relação LL/RLV é de aumento, conforme o coeficiente angular positivo.

Neste caso, vale destacar os períodos 12, 13, 14 e 16 com margem de lucro muito inferior aos demais períodos. Embora a tendência do período posterior a medida seja de aumento, trata-se de uma verificação em relação aos períodos iniciais em que a margem de lucro esteve abaixo dos valores comumente verificados, o que não caracteriza um aumento efetivo da margem de lucro. Para obter uma maior robustez dos dados analisados, utiliza-se o Teste t de Student a fim de identificar se há efetiva diferença das médias entre os dois períodos analisados, conforme se apresenta na Tabela 5. 
Tabela 5 - Teste t para relação LL/RLV

\begin{tabular}{|c|c|c|}
\hline LL/RLV & Antes & Depois \\
\hline Média & $-1,3110$ & $-6,3091$ \\
\hline Variância & 10,0492 & 375,8647 \\
\hline Observações & 10 & 10 \\
\hline Correlação de Pearson & & 0,9664 \\
\hline Hipótese da diferença de média & & 0 \\
\hline $\mathrm{gl}$ & & 9 \\
\hline Stat $\mathrm{t}$ & & $-0,9671$ \\
\hline $\mathrm{P}(\mathrm{T}<=\mathrm{t})$ uni-caudal & & 0,1794 \\
\hline t crítico uni-caudal & & 1,8331 \\
\hline
\end{tabular}

Fonte: Dados da pesquisa

De acordo com a Tabela 5, ao nível de significância de 5\%, os dados não possuem evidência suficiente para rejeitar a hipótese nula como demonstra o valor P de 0,1794 , ou seja, não é possível afirmar que a relação LL/RLV, em média, se altera com as medidas de desoneração.

Pode-se verificar que a média de $-131,10 \%$ da margem de lucro no período anterior a medida da desoneração é superior à média de $-630,91 \%$ da margem de lucro do período posterior a medida da desoneração. Isto acontece devido aos períodos com margem de lucro muito inferior à média, conforme já destacado, que ocorreram nos primeiros períodos após a desoneração e, assim, influenciaram a média do período.

Ao considerar a elevada competitividade entre as empresas do setor têxtil, outra questão relacionada ao não aumento da margem de lucro é que, com a redução dos custos dos produtos vendidos, os gestores podem ter optado pela redução do preço de venda com o objetivo de conquistar mercado e atuar de forma competitiva, o que se configura como mera suposição, uma vez que isso não pode ser comprovado tão somente com as informações apuradas no presente estudo.

\section{CONCLUSÃO}

Sob a ótica do comportamento dos custos, este estudo identificou o impacto das medidas governamentais de desoneração da folha de pagamento nos custos e despesas e, consequentemente, nos resultados das empresas do segmento de fios e tecidos listadas na BM\&FBOVESPA no período de 2009 a 2015. As análises dos efeitos deste evento tomaram por base uma amostra de 11 trimestres antes da desoneração e 16 trimestres após a desoneração, o que possibilitou a visualização de importantes achados a respeito, uma vez que se esperava redução nos custos dos produtos vendidos e nos custos totais, bem como melhorias nos resultados das referidas empresas. 
A análise da linha de tendência permitiu verificar as tendências da relação dos custos, das despesas e da margem de lucro e a receita líquida de vendas antes e após a desoneração da folha de pagamento. Os custos dos produtos vendidos apresentaram tendência de aumento antes da medida, e tendência de queda após a desoneração, assim como os custos totais. No entanto, os custos totais apresentaram média superior após a desoneração da folha. A linha de tendência da margem de lucro, por sua vez, apresentou queda antes da desoneração e aumento após a desoneração ocasionado, sobretudo, pelas elevadas médias dos trimestres iniciais do período após a desoneração.

Com relação ao Teste t, numa análise das variáveis CPV/RLV, CT/RLV e LL/RLV, não há evidência suficiente para rejeitar a hipótese nula de que estas variáveis não se alteraram com a medida da desoneração. Ou seja, não há evidências de que os custos e despesas tiveram efetiva diminuição e que a margem de lucro teve efetivo aumento.

No estudo de Richartz et al. (2011), verificou-se que não existe um comportamento uniforme da relação entre o custos/receitas das empresas pesquisadas, bem como apontou para uma tendência de crescimento da média dos custos/receitas, na qual, cada vez mais, as empresas têm seu lucro bruto reduzido, em termos relativos. Ao relacionar tais resultados com os apresentados na presente pesquisa, infere-se que os custos totais do segmento objeto de estudo, em média, apresentaram aumentos significativos no período analisado, o que demonstra uma tendência de decréscimo da relação CT/RLV.

Já, quanto à relação do impacto de medidas governamentais nos custos das empresas, a presente pesquisa não obteve as mesmas conclusões do estudo de Ferrari, Kremer e Pinheiro (2013), o qual concluiu que os custos das empresas são afetados pela regulação governamental. Ou seja, os achados do presente não corroboram o referido estudo.

Vale mencionar que as inferências aqui apresentadas são válidas somente para as empresas do segmento têxtil de fios e tecidos listadas na BM\&FBOVESPA incluídas nas análises, do primeiro trimestre de 2009 ao terceiro trimestre de 2015, e não podem ser generalizadas para outros segmentos e setores sem as devidas adaptações. Além disso, as conclusões se limitam aos dados analisados no referido período.

Como possibilidade de estudos posteriores, sugere-se a análise de outros setores, os quais também são contemplados pelas medidas governamentais de desoneração da folha de pagamento. Destaca-se, ainda, a necessidade de uma comparação com o número de funcionários dessas empresas com o propósito de verificar o impacto da desoneração nos custos da mão de obra, em particular, de tais segmentos. 


\section{REFERÊNCIAS}

ANSILIERO, G.; LEONARDO, A. R.; PAIVA, L. H.; STIVALI, M.; BARBOSA, E. D.; SILVEIRA, F. G. A desoneração da folha de pagamentos e sua relação com a formalidade no mercado de trabalho. Texto para discussão, Instituto de Pesquisa Econômica Aplicada (IPEA). Brasília: IPEA, 2008.

BANKER, R. D.; BYZALOV, D.; CHEN, L. T. Employment protection legislation, adjustment costs and cross-country differences in cost behavior. Journal of Accounting and Economics, v. 55, n. 1, p. 111-127, 2012.

BM\&FBOVESPA - Bolsa de Valores, Mercadorias e Futuros. Classificação do setor de atuação das companhias. Disponível em:

http://www.bmfbovespa.com.br/ciaslistadas/empresaslistadas/BuscaEmpresaListada.aspx?idi oma=pt-br\#. Acesso em: 22 nov. 2014.

BRASIL. Lei no 8.212/91, de 24 de Julho de 1991. Diário Oficial [da] República Federativa do Brasil, Poder Executivo, Brasília, DF, 24 jul. 1991.

. Emenda Constitucional no 20, de 15 de dezembro de 1998. Diário Oficial [da]

República Federativa do Brasil, Poder Executivo, Brasília, DF, 16 dez. 1998.

. Lei ${ }^{\circ}$ 9.876, de 26 de novembro de 1999. Diário Oficial [da] República

Federativa do Brasil, Poder Executivo, Brasília, DF, 29 nov. 1999.

. Emenda Constitucional no 42, de 19 de dezembro de 2003. Diário Oficial [da]

República Federativa do Brasil, Poder Executivo, Brasília, DF, 31 dez. 2003.

Lei $n^{\circ}$ 12.546, de 14 de dezembro de 2011. Diário Oficial [da] República

Federativa do Brasil, Poder Executivo, Brasília, DF, 15 dez. 2011.

Lei $n^{\circ} 12.715$, de 17 de setembro de 2012. Diário Oficial [da] República

Federativa do Brasil, Poder Executivo, Brasília, DF, 18 set. 2012.

MP n 563, de 04 de abril de 2012. Diário Oficial [da] República Federativa do

Brasil, Poder Executivo, Brasília, DF, 04 abr. 2012.

Decreto Lei $\mathrm{n}^{\circ} 7.828$, de 16 de outubro de 2012. Diário Oficial [da] República

Federativa do Brasil, Poder Executivo, Brasília, DF, 17 out. 2012.

Instrução Normativa RFB no 1.436, de 20 de dezembro de 2013. Diário Oficial

[da] República Federativa do Brasil, Poder Executivo, Brasília, DF, 02 jan. 2014.

Lei $\mathrm{n}^{\circ}$ 13.161, de 31 de agosto de 2015. Diário Oficial [da] República

Federativa do Brasil, Poder Executivo, Brasília, DF, 31 ago. 2015.

CNI. Cartilha Custo Brasil. São Paulo: Confederação Nacional da Indústria. 1995.

FERRARI, M. J.; KREMER, A. W.; PINHEIRO, N. S. Análise do comportamento dos custos no setor de telecomunicações. In: XX Congresso Brasileiro de Custos, Uberlândia, 2013.

Anais... Uberlândia: CBC, 2013. 
FIESC - Federação das Indústrias do estado de Santa Catarina. Notícias: Têxteis de SC querem aumentar negócios com a América do Sul. Florianópolis, 2011. Disponível em: http://www2.fiescnet.com.br/web/pt/site topo/fiesc/noticias /show/page/3/ tipo Noticia/2/id/9338/portalId/2. Acesso em: 20 jan. 2014.

GARRISON, R. H; NOREEN, E. W; BREWER, P. C. Contabilidade gerencial. Rio de Janeiro: LTC, 2007.

GUENTHER, T. W.; RIEHL, A.; RÖBLER, R. Cost stickiness: state of the art of research and implications. Journal of Management Control, v. 24, n. 4, p. 301-318, 2014.

HANSEN, D. R.; MOWEN, M. M. Gestão de custos: contabilidade e controle. São Paulo: Pioneira Thomson Learning: Cengage Learning, 2001.

KERTZMAN, I. A desoneração da folha de pagamento. 218 f. Dissertações (Mestrado em Direito) - Universidade Federal da Bahia, Bahia, 2012.

MEDEIROS, O. R.; COSTA, P. S.; SILVA, C. A. T. Testes empíricos sobre o comportamento assimétrico dos custos nas empresas brasileiras. Revista Contabilidade e Finanças, São Paulo, p. 47-56, 15 mar. 2005.

OLIVEIRA, D. O. A cultura dos assuntos públicos: o caso do "Custo Brasil”. Revista de Sociologia e Política. n. 14, p. 139-161, jun. 2000.

OLIVEIRA, P. H. D.; LUSTOSA, P. R. B.; SALES, I. C. H. Comportamento de custos como parâmetro de eficiência produtiva: uma análise empírica da Companhia Vale Do Rio Doce antes e após a privatização. Revista Universo Contábil, v. 3, n. 3, p. 54-70, 2007.

PLANO BRASIL MAIOR. Plano Brasil Maior: Inovar para competir. Competir para crescer. Disponível em: http://www.brasilmaior.mdic.gov.br/conteudo/128. Acesso em: 16 dez. 2013.

RICHARTZ, F.; NUNES, P.; BORGERT, A.; DOROW, A. Comportamento dos custos das empresas catarinenses que atuam no segmento fios e tecidos da BM\&FBOVESPA. In: XVIII Congresso Brasileiro de Custos, Rio de Janeiro, 2011. Anais... Rio de Janeiro: CBC, 2011.

RICHARTZ, F.; BORGERT, A.; FERRARI, M. J; VICENTE, E. F. R. Comportamento dos custos das empresas brasileiras listadas no segmento de fios e tecidos da BM\&FBOVESPA entre 1998 e 2010. In: XIX Congresso Brasileiro de Custos, Bento Gonçalves, 2012. Anais... Bento Gonçalves: CBC, 2012.

RICHARTZ, F.; BORGERT, A. O comportamento dos custos das empresas brasileiras listadas na BM\&FBOVESPA entre 1994 e 2011. In: VII Congresso ANPCONT, Fortaleza, 2014. Anais... Fortaleza: ANPCONT, 2013.

VIEIRA, D. P. Facilitadores no processo de inovação tecnológica. Tese (Doutorado em Engenharia de Produção) - Universidade Federal de Santa Catarina, Centro Tecnológico, Florianópolis, 1995. 